\title{
Exigência de Lisina para Aves de Reposição de 13 a 20 Semanas de Idade ${ }^{1}$ \\ José Humberto Vilar da Silva ${ }^{2}$, Luiz Fernando Teixeira Albino ${ }^{3}$, Horacio Santiago Rostagno ${ }^{3}$, Paulo César Gomes ${ }^{3}$, Ricardo Frederico Euclydes ${ }^{3}$
}

\begin{abstract}
RESUMO - Objetivando estimar as exigências de lisina de 13 a 20 semanas e avaliar seus efeitos na fase de produção de ovos, 200 poedeiras leves (PL) Lohmann Selected Leghorn e 200 poedeiras semipesadas (PSP) Isa Brown foram distribuídas em delineamento em blocos ao acaso e alimentadas com ração basal contendo 14,0\% de proteína bruta (PB) e 2.900 kcal de energia metabolizável (EM) suplementada com L-lisina $\mathrm{HCl}$ para os níveis de 0,$39 ; 0,42 ; 0,45 ; 0,48$; e $0,51 \%$ de lisina total nas rações. Na fase de postura, 160 aves de cada linhagem foram alimentadas com ração de produção contendo $16,5 \%$ de $\mathrm{PB}, 2.900 \mathrm{kcal} / \mathrm{kg}$ de EM, $2,9 \%$ de $\mathrm{Ca}^{+2}$ e $0,755 \%$ de lisina. As estimativas das exigências de lisina obtidas pelo ganho de peso, para a fase de 13 a 20 semanas de idade, foram de $0,48 \%$ ou consumo de $354 \mathrm{mg}$ diário para as PL e de $0,49 \%$ ou consumo de $365 \mathrm{mg}$ diário para as PSP. Produção de ovos e conversões por massa e por dúzia de ovos de ambas as linhagens foram afetadas de forma quadrática pelos níveis de lisina da fase de crescimento. A massa de ovos das PL foi afetada de forma quadrática. Durante a fase de crescimento, as PSP apresentaram maior ganho de peso que as PL. Durante a fase de produção, as PSP apresentaram menor consumo de ração e melhor conversão alimentar por massa de ovos que as PL.
\end{abstract}

Palavras-chave: aminoácido, crescimento, produção e massa de ovos.

\section{Requirement of Lysine for Rearing Egg-Type Pullets from 13 to 20 Weeks of Age ${ }^{1}$}

ABSTRACT - The objective of this work was to estimate the requirement of lysine from 13 to 20 weeks and to evaluate the posterior effect on the performance of two egg-type strains. Three hundred egg-white pullets from 13 to 20 weeks of age and three hundred eggbrown pullets from 13 to 20 weeks of age were allotted to a randomised block design with five treatments and four replicates. A basal diet with $14.0 \%$ of crude protein and $2900 \mathrm{kcal}$ metabolizable energy $/ \mathrm{kg}$ was supplemented with L-lysine $\mathrm{HCl}$ to obtain $0.39,0.42,0.45$, 0.48 , and $0.51 \%$ of total lysine in the diet. During the laying period, all hens received the same diet with $16.5 \mathrm{CP}, 2822 \mathrm{kcal} \mathrm{ME} / \mathrm{kg}$, $3.81 \% \mathrm{Ca}^{+2}$ and $0.755 \%$ of lysine. The pullets requirement estimates of lysine based on weight gain from 13 to 20 weeks were $0.48 \%$ or a daily intake of $354 \mathrm{mg}$ for white-egg, and $0.49 \%$ or a daily intake of $365 \mathrm{mg}$ for brown-egg. Egg production and mass and egg dozen conversions of two strains were quadraticly affected. Egg mass of white-egg was affected by quadratic manner. During the final growing phase, the brown-egg pullets showed better weight gain than white-egg pullets. During the egg production phase, the brown-egg pullets showed a lower feed intake and better egg mass conversion than white-egg pullets.

Key Words: amino acid, growth, egg production, egg mass

\section{Introdução}

O conhecimento da curva de crescimento das aves de reposição tem mostrado que $70 \%$ do peso adulto de uma poedeira deve ser atingido até as 12 semanas (FARIA e JUNQUEIRA, 1998), 82\% até as 15 semanas, e $92 \%$ até as 22 semanas, enquanto os $8 \%$ restante deve ser ganho posteriormente (KWAKKEL, 1992).

$\mathrm{Na}$ fase de crescimento final, o ganho de peso de cerca de 400 a $500 \mathrm{~g}$ é influenciado pelo acréscimo nos pesos do fígado (PENZ JUNIOR, 1991) e nas estruturas vitais para o adequado desempenho de produção, como o ovário e o oviduto, com pique de crescimento em torno da 19aㅗ semana (KWAKKEL, 1992).
A maioria das informações sobre exigências de poedeiras foi obtida em regiões de clima ameno, e sabe-se que, em condições tropicais, as altas temperaturas diurnas estressam as aves, afetando negativamente o consumo de ração, o crescimento e o desempenho produtivo em relação às aves criadas em clima temperado (DEVEGOWDA, 1992, e LEESON e SUMMERS, 1997), retardando a maturidade sexual das aves e, provavelmente, a troca da ração de crescimento final para a ração de produção.

Entretanto, os recentes ganhos genéticos obtidos com a introdução dos genes do nanismo nas aves semipesadas, a partir dos anos 80 , com redução do peso e do consumo de ração, além de melhor conversão

\footnotetext{
${ }^{1}$ Parte da Tese de Doutorado do primeiro autor. Bolsista do convênio PICDT-Capes/UFPB.

2 Departamento de Agropecuária - CFT/UFPB - Bananeiras - PB - CEP 58.220-000. E.mail: jvilar@cft.ufpb.br

${ }^{3}$ Professor do Departamento de Zootecnia da UFV. Viçosa, MG, Brasil. CEP. 36.570-000.
} 
alimentar (FLOCK, 1998), fez surgir novas demandas para atualização da informação das exigências de poedeiras em crescimento e das diferenças das necessidades das aves semipesadas em relação às das leves.

A publicação do NATIONAL RESEARCH COUNCIL - NRC (1994) ainda não refletiu essas mudanças, em virtude da escassez de informações das exigências das aves leves e semipesadas à época. Um exemplo, as recomendações de lisina para a fase final de crescimento foram derivadas de dois trabalhos publicados na décadas de 70 (BERG, 1976) e 80 (KESHAVARZ, 1984) com aves legornes, em que os resultados foram extrapolados para obter as exigências das aves semipesadas, considerando-se o maior peso, o apetite e a maior exigência de mantença dessas linhagens.

Por outro lado, sérias discordâncias são encontradas na literatura nas recomendações dos aminoácidos e no início e término das fases do crescimento, tornando a formulação de ração para poedeiras em crescimento uma tarefa difícil.

No período de 13 a 20 semanas de idade, ROSTAGNO et al. (1983) recomendaram 0,55\% de lisina para rações com $2.900 \mathrm{kcal}$ de energia metabolizável e $14 \%$ de proteína bruta. Ja o NRC (1994) sugeriu 0,45 e 0,42\%, respectivamente, para as aves leves e semipesadas.

Dados mais recentes mostraram que', na fase final de crescimento, níveis de lisina acima de $0,46 \%$ na ração com 2.930 kcal EM não melhoraram a taxa de crescimento de aves semipesadas (LEESON e SUMMERS, 1997), sendo este nível similar ao recomendado para as aves leves.

Por outro lado, os manuais das linhagens comerciais trazem valores muito além dos normalmente encontrados nas tabelas convencionais. O MANUAL DA LINHAGEM LOHMANN LSL (1997) sugeriu $0,70 \%$ de 8 a 18 semanas e o MANUAL DA LINHAGEM ISA BROWN (1996), 0,74\% de lisina de 10 a 16 semanas de idade.

Os objetivos deste trabalho foram atualizar as exigências em lisina de poedeiras leves e semipesadas de 13 a 20 semanas de idade e avaliar o efeito desses níveis sobre o rendimento produtivo das aves.

\section{Material e Métodos}

O experimento foi realizado no Aviário do Departamento de Zootecnia da Universidade Federal de Viçosa, no período de 05 de junho de 1997 a 11 de março de 1998.

\section{Fase de crescimento}

Um total de 400 aves, 200 poedeiras leves (PL) Lohmann Selected Leghorn e 200 poedeiras semipesadas (PSP) ISA-Brown, foi identificado por tratamento e criado em condições convencionais com rações balanceadas para todos os nutrientes, fornecidas à vontade até às 12 semanas. Aos 10 dias de idade, as aves foram debicadas para prevenção de canibalismo, iniciando-se esquema básico de vacinação e controle das principais enfermidades das aves de postura.

No início da fase de produção, as aves pesadas foram transferidas para os boxes de 1 x 2 m do galpão experimental, onde permaneceram até as 20 semanas de idade. Foram usados cama de maravalha, um comedouro tubular e um bebedouro pendular em cada boxe.

Uma ração basal deficiente em lisina com 14,0\% de proteína bruta (NRC, 1994) e $2900 \mathrm{kcal} \mathrm{de} \mathrm{EM/kg}$ (ROSTAGNO et al., 1983) foi suplementada com 0,$000 ; 0,038 ; 0,076 ; 0,115 ;$ e $0,153 \%$ de L-lisina $\mathrm{HCl}$ de forma a proporcionar cinco níveis de lisina nas rações de 0,$39 ; 0,42 ; 0,45 ; 0,48$; e $0,51 \%$ (Tabela 1 ). Inicialmente, as duas misturas das extremidades foram preparadas e seguidas por uma série de diluições para se obterem as rações com níveis intermediários.

O sorgo de baixo tanino e o glúten de milho foram incluídos em substituição ao milho e farelo de soja, para reduzir o conteúdo de lisina da ração basal e por serem, respectivamente, boas fontes de energia e proteína em rações de aves.

Os parâmetros avaliados foram consumo de ração e lisina, ganho de peso e conversão alimentar. Com a conclusão da fase experimental, as aves permaneceram no mesmo recinto até as 22 semanas.

\section{Fase de postura}

O galpão de postura, de $60 \times 9 \mathrm{~m}$, com telas nas laterais à prova de pássaro, coberto com telhas de barro em duas águas, apresentava dois conjuntos de quatro fileiras de gaiolas, separadas por um corredor central de $2 \mathrm{~m}$, sendo utilizadas apenas duas fileiras centrais de cada conjunto. Durante a fase de produção, o fotoperíodo utilizado foi de 16 horas por dia.

Às 22 semanas, 160 frangas Lohmann LSL e 160 Isa Brown foram pesadas e transferidas do piso para as gaiolas de produção. As aves foram alojadas ao acaso em quatro repetições por tratamento, cada uma com oito aves. A água foi distribuída em bebedouros de água corrente de alumínio, tipo V, localizados acima dos comedouros.

Uma ração de produção (Tabela 1) foi fornecida à vontade a todas as aves, com a finalidade de 
Rev. bras. zootec.

Tabela 1 - Composições da ração basal de 13 a 20 semanas e da ração de produção ${ }^{1}$

Table 1 - Compositions of the basal diet from 13 to 20 weeks and production diet

\begin{tabular}{|c|c|c|}
\hline $\begin{array}{l}\text { Componentes } \\
\text { Components }\end{array}$ & $\begin{array}{l}\text { Final } \\
\text { Final }\end{array}$ & $\begin{array}{l}\text { Produção de ovos } \\
\text { Egg production }\end{array}$ \\
\hline Milho, $8,07 \% \mathrm{~PB}^{3}$ (Corn) & 38,000 & 66,307 \\
\hline Farelo de soja, $45,79 \% \mathrm{~PB}^{3}$ (Soybean meal) & 4,780 & 19,812 \\
\hline Sorgo baixo tanino, $8,82 \% \mathrm{~PB}^{3}$ (Sorghum, low tanin) & 37,000 & - \\
\hline Glúten de milho, $60,90 \% \mathrm{~PB}^{3}$ (Corn gluten meal) & 8,740 & 2,795 \\
\hline Amido (Starch) & 0,200 & - \\
\hline Calcário (Limestone) & 1,280 & 8,801 \\
\hline Fosfato bicálcico (Dicalcium phosphate) & 1,176 & 1,629 \\
\hline DL-metionina (DL-methionine) & - & 0,071 \\
\hline Premix mineral (Mineral premix) ${ }^{4}$ & 0,050 & 0,050 \\
\hline Premix vitamínico (Vitamin premix) ${ }^{5}$ & 0,100 & 0,100 \\
\hline Cloreto de colina (Choline chloride) & 0,020 & 0,020 \\
\hline Bacitracina de zinco (Zinc bacitracin) & 0,025 & 0,010 \\
\hline Sal (Salt) & 0,330 & 0,396 \\
\hline BHT & 0,010 & 0,010 \\
\hline Anticoccidiano (Coccidiostatic) & 0,050 & - \\
\hline Caulin & 8,239 & - \\
\hline \multicolumn{3}{|l|}{$\begin{array}{l}\text { Composição calculada } \\
\text { Calculated composition }\end{array}$} \\
\hline Proteína bruta (Crude protein), \% & 14,000 & 16,500 \\
\hline $\mathrm{EM}(M E), \mathrm{kcal} / \mathrm{kg}$ & 2900 & 2822 \\
\hline Cálcio (Calcium), \% & 0,800 & 3,810 \\
\hline Fósforo disponível (Available phosphorus), \% & 0,300 & 0,400 \\
\hline Lisina (Lysine), \% & 0,390 & 0,755 \\
\hline Metionina + Cistina $($ Met + Cys $), \%$ & 0,592 & 0,647 \\
\hline Metionina (Methionine), \% & 0,293 & 0,361 \\
\hline Treonina (Threonine), \% & 0,514 & 0,640 \\
\hline Triptofano (Tryptophan), \% & 0,120 & 0,198 \\
\hline Sódio (Sodium), \% & 0,150 & 0,190 \\
\hline \multicolumn{3}{|c|}{ 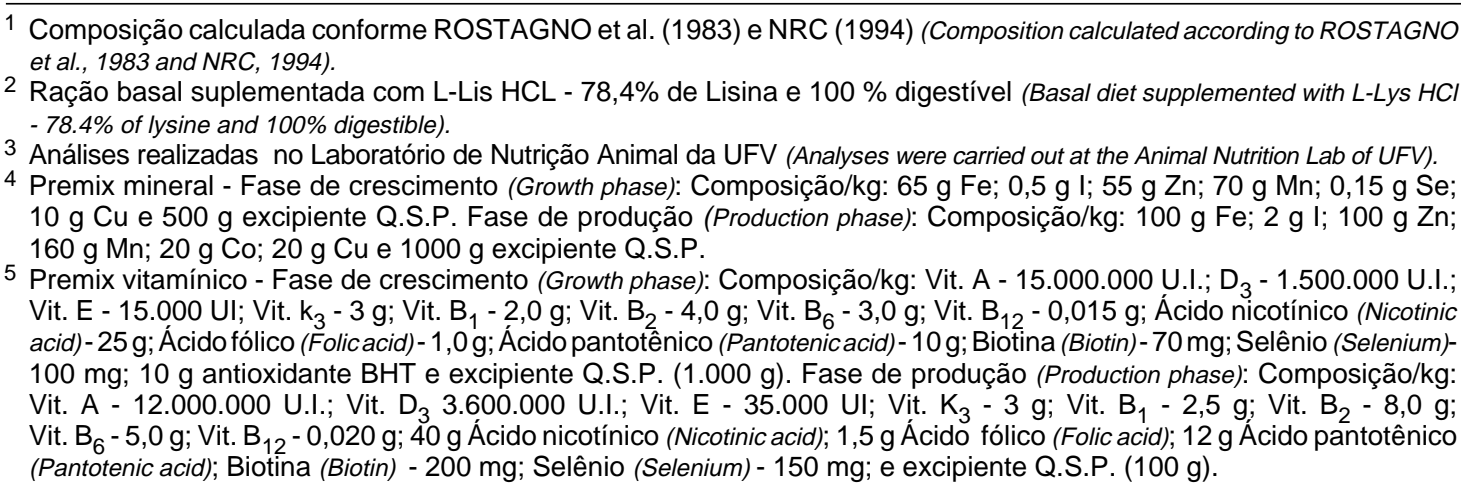 } \\
\hline
\end{tabular}

permitir a avaliação do efeito residual dos níveis de lisina do período de 13 a 20 semanas, sendo formulada para atender ou exceder as exigências das aves em energia metabolizável, proteína e lisina, conforme ROSTAGNO et al. (1996), e demais nutrientes incluídos, de acordo com o NRC (1994).

Os dados de postura foram obtidos em quatro períodos de 28 dias ( 26 a 42 semanas). No início e final de cada período, as aves e rações foram pesadas. A produção de ovos foi anotada diariamente e os ovos produzidos nos últimos cinco dias de cada período foram pesados nos dias posteriores às coletas. As variáveis estudadas foram produção de ovos, consumo de ração, peso e massa de ovos e conversões por massa e dúzia de ovos.

O experimento foi realizado em um delineamento em blocos casualizados em esquema fatorial $5 \times 2$ (cinco níveis de lisina e duas linhagens de postura comercial), com quatro repetições de 15 aves de 13 a 20 semanas e oito aves durante o período de produção, empregando o seguinte modelo estatístico:

$$
\mathrm{Y}_{\mathrm{ijkl}}=\mu+\mathrm{B}_{1}+\mathrm{N}_{\mathrm{i}}+\mathrm{L}_{\mathrm{j}}+\mathrm{N}_{\mathrm{i}}{ }^{*} \mathrm{~L}_{\mathrm{j}}+\mathrm{e}_{\mathrm{ijkl}}
$$

em que $\mathrm{Y}_{\mathrm{ijkl}}$ é observação relativa à $\mathrm{k}^{\text {-éssima unidade }}$ experimental que recebeu oi-éssimo nível de lisinae aj-éssima linhagem $\mathrm{j}, \mathrm{l}^{\text {-éssimo }}$ bloco; $\mu$, média geral do experimento; $\mathrm{B}_{1}$, efeito do $\mathrm{l}^{\text {-éssimo }}$ bloco, sendo $\mathrm{l}=1, \ldots 4 ; \mathrm{N}_{\mathrm{i}}$, efeito do 


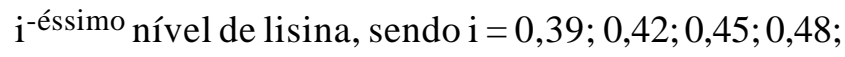
e $0,51 \% ; L_{j}$, efeito daj-éssima linhagem, sendo $=1$ e $2 ; N_{i}$ $* \mathrm{~L}_{\mathrm{j}}$, efeito de interação dos níveis de lisina i e a linhagem $\mathrm{j}$; $\mathrm{e}_{\mathrm{ijkl}}$, erro experimental, sendo o erro $\operatorname{NID}\left(0, \sigma^{2}\right)$.

As somas de quadrados dos tratamentos foram desdobradas nos efeitos lineares, quadráticos, cúbicos e quárticos, conforme procedimento do SAEG (UNIVERSIDADE FEDERAL DE VIÇOSA - UFV, 1982). As exigências de lisina de cada linhagem foram estimadas pelo modelo de regressão quadrático, considerando-se o coeficiente de determinação $\left(\mathrm{R}^{2}\right)$ e a interpretação biológica dos parâmetros.

Os valores estimados das exigências de lisina foram empregados para obter a relação ideal com os valores calculados de aminoácidos importantes na ração de poedeiras em crescimento e comparados com a relação obtida da recomendação de aminoácido total do NRC (1994).

\section{Consumo diário de lisina total e digestível}

As quantidades diárias de lisina total a serem fornecidas às aves foram obtidas considerando as estimativas percentuais das exigências de lisina, como variável independente das equações de regressão linear dos consumos de lisina total, em função da concentração de lisina total na ração. Em seguida, os valores calculados de lisina total foram multiplicados pelo coeficiente de digestibilidade verdadeira de lisina de 89\% (ROSTAGNO, et al., 1996), para obtenção da quantidade diária de lisina digestível.

\section{Resultados e Discussão}

\section{Temperatura ambiente}

A temperatura na fase de 13 a 20 semanas variou de 11,0 a $25,8^{\circ} \mathrm{C}$ e, provavelmente, não limitou o consumo de ração das aves. Na fase de postura, a temperatura variou de 17,5 a $32,0^{\circ} \mathrm{C}$. As médias diurnas de 30 a 42 semanas foram superiores a $30^{\circ} \mathrm{C} \mathrm{e}$, apesar das controvérsias a respeito da zona termoneutra das aves, segundo CHARLES (1992), exposições prolongadas a temperaturas maiores que $27^{\circ} \mathrm{C}$ são perigosas para a sobrevivência das poedeiras.

\section{Desempenho na fase de crescimento}

Existiram efeitos quadráticos $(\mathrm{P}<0,05)$ para o ganho de peso, com estimativas das exigências de lisina de $0,48 \%$ para a linhagem leve e $0,49 \%$ para a linhagem semipesada (Tabela 2 e Figura 1).

Coerentes com os resultados dos ensaios anteriores (SILVA et al., 2000ab), estas estimativas foram maiores que as do NRC (1994), 0,45\% para a linhagem leve e $0,42 \%$ para a semipesada, e inferiores ao valor de $0,55 \%$ de lisina prescrito por ROSTAGNO et al. (1983). A estimativa obtida para as aves semipesadas foi levemente superior àquela descrita por LEESON e SUMMERS (1997) de 0,46\%. Foi observado que as aves leves apresentaram exigência de lisina $2 \%$ inferior àquela das aves semipesadas.

Pelos resultados obtidos neste experimento, infere-se que as aves leves e semipesadas apresentaram

Tabela 2 - Ganho de peso (GP), consumo de ração (CR), conversão alimentar (CA) e consumo de lisina (CL) de poedeiras leves (PL) e semipesadas (PSP) no período de 13 a 20 semanas de idade

Table 2 - Average weight gain (WG), feed intake (FI), feed: gain ratio (F/G) and lysine intake (LI) of white-egg layer hens (LL) and brownegg layer hens $(H L)$ from 13 to 20 weeks of age

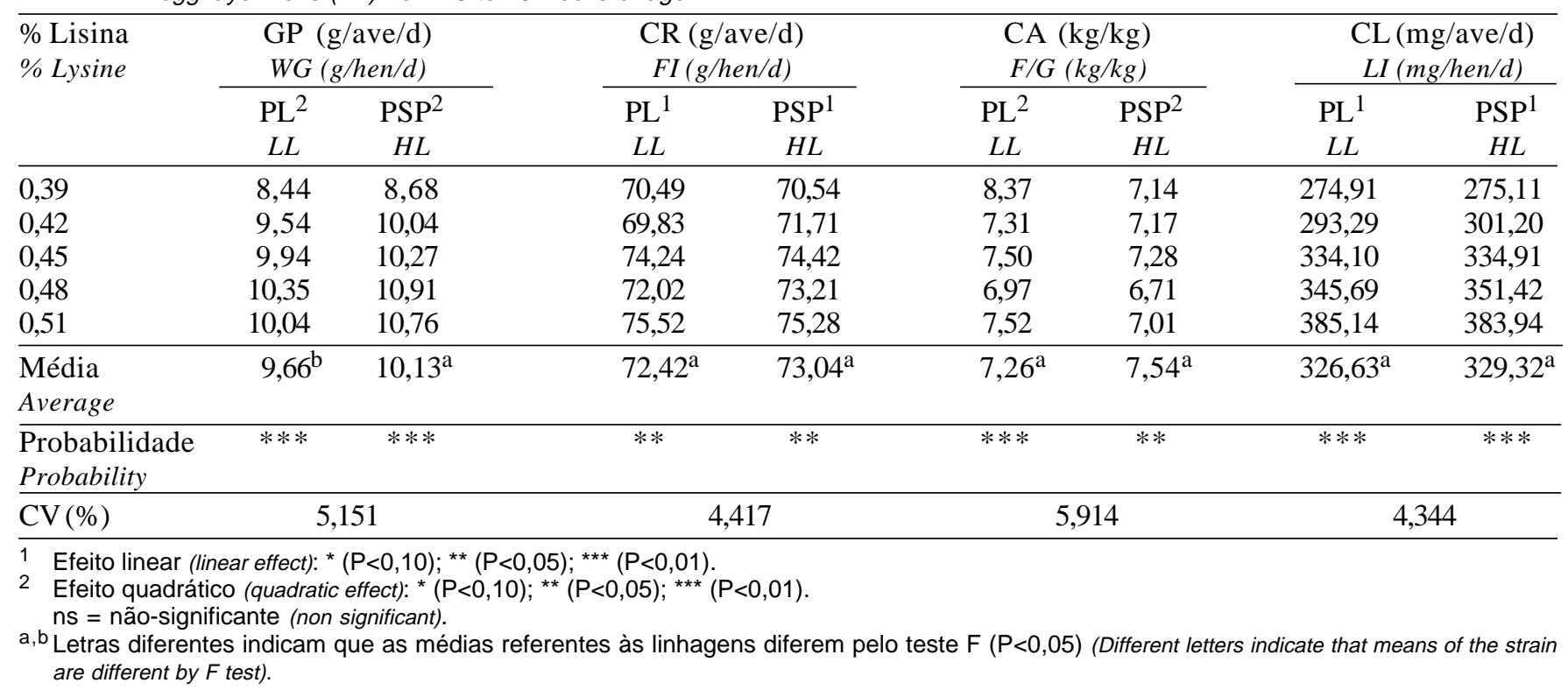




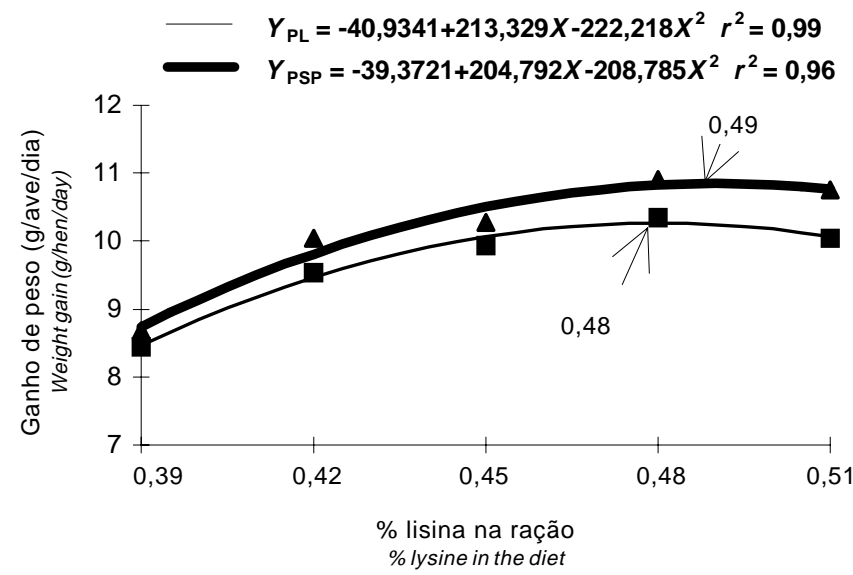

Figura 1 - Ganho de peso das aves, em função do nível de lisina na ração.

Figure 1 - Average weight gain of laying hens, in function of dietary lysine level.

ótimos crescimentos, com níveis de lisina na ração inferiores aos recomendados nos manuais dessas linhagens, de $0,70 \%$ (MANUAL DA LINHAGEM LOHMANN, 1997) e 0,74\% (MANUAL DA LINHAGEM ISA BROWN, 1997).

O consumo de ração cresceu linearmente $(\mathrm{P}<0,05)$ (Tabela 2), mas a conversão alimentar de ambas as linhagens foi afetada de forma quadrática pelos extremos de lisina nas rações (Tabela 7 e Figura 2), com exigências estimadas de $0,47 \%$ para as aves leves $(\mathrm{P}<0,01)$ e $0,48 \%$ para as semipesadas $(\mathrm{P}<0,05)$, sendo ligeiramente menores que as obtidas pelo ganho de peso.

O consumo de lisina cresceu de forma linear $(\mathrm{P}<0,01)$ com o aumento da concentração de lisina nas rações (Tabela 2 e Figura 3). Estes resultados foram consistentes com os observados nas fases de 0 a 6 e de 7 a 12 semanas de idade (SILVA et al., 2000a,b).

As quantidades diárias de lisina estimadas para atender às exigências das aves leves e semipesadas foram de 354 e $365 \mathrm{mg}$ de lisina total/ave/dia, respectivamente. Considerando a digestibilidade de lisina de 89\% (ROSTAGNO et al., 1996), as exigências de lisina digestível para as aves leves e semipesadas foram de $0,43 \%$ ou $315 \mathrm{mg} /$ dia/ave e de $0,44 \%$ ou $324 \mathrm{mg} / \mathrm{dia} / \mathrm{ave}$, respectivamente.

Estes resultados reforçam as conclusões das fases anteriores (SILVA et al., 2000ab), em que as exigências das aves semipesadas foram maiores que as das aves leves, que apresentaram valor exigido de lisina muito próximo, enquanto as semipesadas acima da recomendação do NRC (1994), que demonstra a necessidade de atualização das recomendações das aves semipesadas.

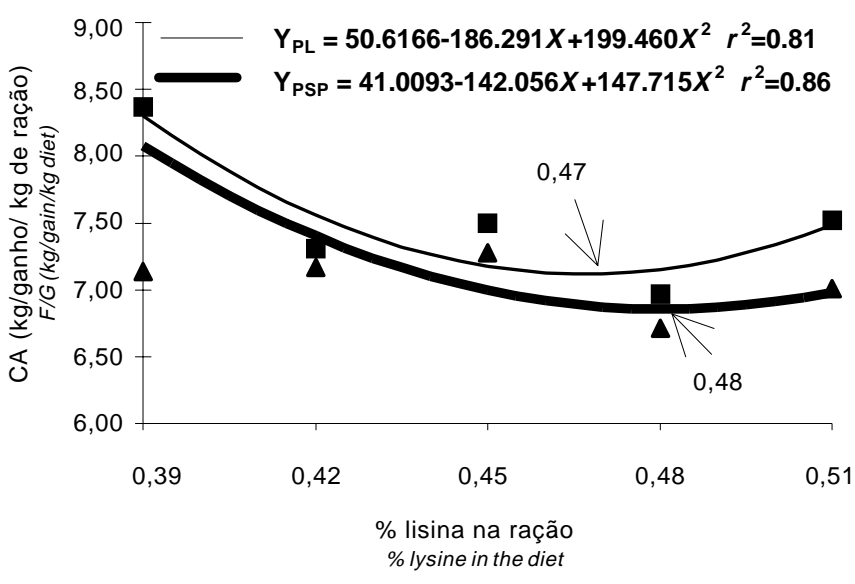

Figura 2 - Conversão alimentar, em função dos níveis de lisina na ração no período de 13 a 20 semanas de idade.

Figure 2 - Feed:gain ratio, in function of dietary lysine level from 13 to 20 weeks of age.

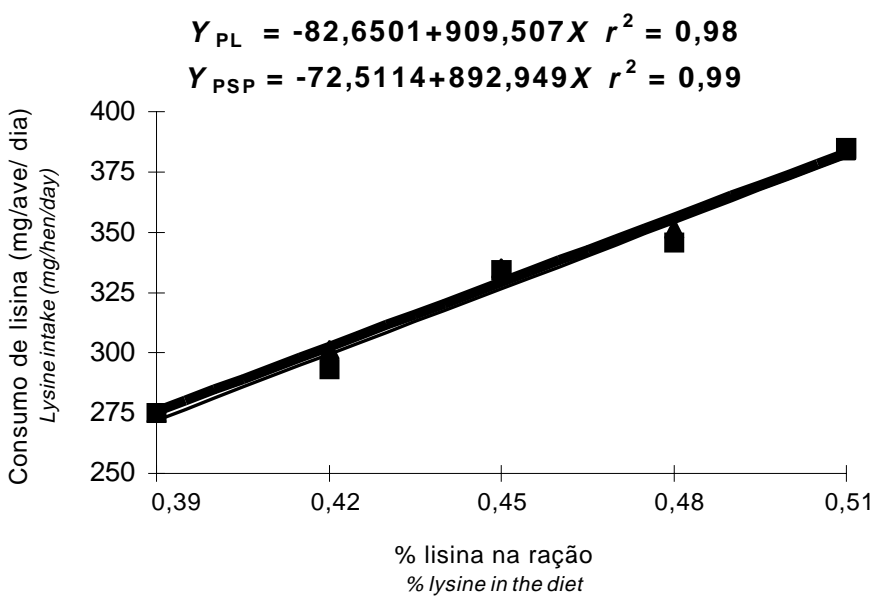

Figura 3 - Consumo de lisina, em função dos níveis de lisina na ração no período de 13 a 20 semanas de idade.

Figure 3 - Lysine intake of laying hens, in function of dietary lysine level from 13 to 20 weeks of age.

Não existiram diferenças significativas $(\mathrm{P}>0,05)$ entre as linhagens quanto ao consumo de ração, à conversão alimentar e ao consumo de lisina no período de crescimento. Entretanto, as aves semipesadas apresentaram maior média de ganho de peso diário $(\mathrm{P}<0,05)$ que as leves (Tabela 2$)$.

As relações de lisina e metionina, aminoácidos sulfurosos, treonina e triptofano obtidas no presente estudo foram superiores às relações para ambas as linhagens descritas pelo NRC (1994), sugerindo maior concentração desses aminoácidos em relação à lisina (Tabela 3). As relações lisina:proteína das duas linhagens e lisina:energia das semipesadas também foram maiores que as do NRC (1994), sugerindo maior quantidade de lisina na ração des- 
1800

Tabela 3 - Balanço ideal de aminoácidos em rações de poedeiras comerciais, expresso como percentagem de lisina total

Table 3 - Ideal amino acids balance in commercial laying hens diet, express as percentage of total lysine

\begin{tabular}{|c|c|c|c|c|}
\hline \multirow[t]{2}{*}{$\begin{array}{l}\text { Aminoácidos } \\
\text { Amino acids }\end{array}$} & \multicolumn{2}{|c|}{$\begin{array}{l}\text { Poedeiras leves } \\
\text { White-egg } \\
\text { layerhens } \\
\end{array}$} & \multicolumn{2}{|c|}{$\begin{array}{c}\text { Poedeiras semipesadas } \\
\text { Brown-egg } \\
\text { layer hens }\end{array}$} \\
\hline & $\begin{array}{l}\text { UFV } \\
(1999)\end{array}$ & $\begin{array}{c}\text { NRC } \\
(1994)\end{array}$ & $\begin{array}{c}\text { UFV } \\
\text { (1999) }\end{array}$ & $\begin{array}{l}\text { NRC } \\
(1994)\end{array}$ \\
\hline $\begin{array}{l}\text { Lisina } \\
\text { Lysine }\end{array}$ & 100 & 100 & 100 & 100 \\
\hline $\begin{array}{l}\text { Metionina } \\
\text { Methionine }\end{array}$ & 61 & 44 & 60 & 35 \\
\hline $\begin{array}{l}\text { Met }+ \text { Cis } \\
M e t+C y s\end{array}$ & 123 & 93 & 121 & 74 \\
\hline $\begin{array}{l}\text { Treonina } \\
\text { Threonine }\end{array}$ & 107 & 82 & 105 & 80 \\
\hline $\begin{array}{l}\text { Triptofano } \\
\text { Tryptophan }\end{array}$ & 22 & 24 & 24 & 20 \\
\hline $\begin{array}{l}\text { RelaçãoLis:PB } \\
\text { Lys:CP ratio }\end{array}$ & 3,43 & 3,00 & 3,50 & 3,00 \\
\hline $\begin{array}{l}\text { RelaçãoLis:EM } \\
\text { Lys:ME ratio }\end{array}$ & 0,16 & 0,16 & 0,17 & 0,15 \\
\hline
\end{tabular}

sas linhagens em relação à proteína e das semipesadas em relação à energia.

A relação lisina:aminoácidos sulfurosos cresceu em comparação às fases anteriores (SILVA et al., 2000ab), sendo consistente com o aumento da deposição de proteína nas penas, rica em cistina e metionina, e a queda na taxa de crescimento da proteína muscular, dependente de lisina. Essa hipótese é coerente com as informações de outros autores (BAKER e HAN, 1994; PACK, 1995; e MARTIN et al., 1994).

O uso de aves geneticamente diferentes, os alimentos distintos e as diferentes condições experimentais foram as causas prováveis das discrepâncias no relacionamento lisina e demais nutrientes deste experimento para a tabela convencional.

Os maiores ganhos de peso de 580 e $611 \mathrm{~g}$, respectivamente, para as leves e semipesadas, obtidos no tratamento com $0,48 \%$ de lisina, sugerem que parte significativa do ganho de peso ocorre no final da recria. Esses resultados foram consistentes com o ganho esperado para a fase de 400 a $500 \mathrm{~g}$ (PENZ JR., 1998) e influenciados pelos crescimentos das estruturas vitais para a produção de ovos, como ovário, oviduto, tecido adiposo (KWAKKEL, 1992) e fígado.

\section{Fase de postura}

Vários autores têm afirmado que a composição do corpo é mais importante que o peso corporal no preparo do organismo da ave para a produção de ovos (WELLS, 1980; JOHNSON et al., 1985; CHI, 1985; Leeson, 1986, citado por PENZ JR., 1991; SUMMERS et al., 1987; KWAKKEL et al., 1991; KWAKKEL, 1992; e LEESON e SUMMERS, 1997), portanto os resultados deste estudo são consistentes com esta afirmação.

Os tratamentos com 0,$39 ; 0,42 ; 0,45 ; 0,48$; e $0,51 \%$ de lisina resultaram em início da postura aos $140,137,136,140$ e 145 dias nas leves e aos 139, 135, 133,133 e 133 dias nas semipesadas. Observaram-se atrasos na maturidade sexual de 4 e 6 dias, respectivamente, para as aves leves e semipesadas alimentadas com o nível de $0,39 \%$ de lisina, em comparação ao nível de $0,45 \%$. Estes resultados são consistentes com os atrasos na maturidade sexual de matrizes (COUCH et al., 1967) e poedeiras leves (CONNOR et al., 1977, e KWAKKEL et al., 1991), submetidas às rações deficientes em lisina, em relação às aves com níveis adequados.

A linhagem semipesada iniciou a produção, em média, aos 135 dias e as leves, aos 139 dias.

Similar ao atraso verificado na maturidade sexual, a deficiência de lisina retardou a idade, em que as aves leves atingiram $50 \%$ de produção em média cinco dias e das semipesadas em média um dia, quando as aves receberam as rações contendo 0,39 e $0,42 \%$ de lisina em comparação com as rações com 0,45 a $0,51 \%$ de lisina. Estes resultados sugerem que o fornecimento inadequado de lisina na ração de crescimento final afeta negativamente a maturidade sexual e, conseqüentemente, a idade das aves, ao atingirem $50 \%$ de produção.

As poedeiras leves atrasaram, em média, dois dias $(\mathrm{P}<0,05)$ para atingir $50 \%$ de produção em relação às poedeiras semipesadas.

Existiram efeitos quadráticos para produção de ovos, conversão por massa (Figuras 4 e 5) e conversão por dúzia de ovos $(\mathrm{P}<0,05)$ de ambas as linhagens (Tabela 4). As exigências de lisina variaram de 0,45 a $0,46 \%$ para as aves leves, enquanto o resultado para as semipesadas foi de $0,45 \%$.

Estes resultados discordam dos obtidos por COUCH et al. (1967), que observaram maior produção para as matrizes alimentadas com ração pobre em lisina na fase de crescimento e sugerem danos irreversíveis ao organismo das aves comerciais, impossíveis de serem recuperados até as 42 semanas de idade. Dessa forma, a restrição de lisina durante a fase final do crescimento deve ser evitada. 
Rev. bras. zootec.

Tabela 4 - Efeitos residuais dos níveis de lisina na ração no período de 13 a 20 semanas sobre os parâmetros de produção de ovos (PR), consumo de ração (CR), peso dos ovos (PO), massa de ovos (MO), conversão por massa de ovos (CMO), conversão por dúzia de ovos (CDO) e percentagem de ovos com casca quebrada (OCQ)

Table 4 - Residuals effect of dietary lysine levels from 13 to 20 weeks period on the parameters of egg production (EP), feed intake (FI), egg weight (EW), egg mass (EM), egg mass conversion (EMC), egg dozen conversion (EDC) and percentage of egg shell broken (ESB)

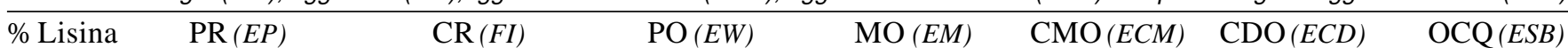

$\begin{array}{lllllll}\% \text { Lysine } & \text { (\%/ave/dia }) \quad(\mathrm{g} / \mathrm{ave} / \mathrm{dia}) & (\mathrm{g} / \mathrm{ave} / \mathrm{dia}) & (\mathrm{g} / \mathrm{ave} / \mathrm{dia}) & (\mathrm{kg} / \mathrm{kg}) & (\mathrm{kg} / \mathrm{dz} .) & (\% / \mathrm{ave} / \mathrm{dia})\end{array}$

\begin{tabular}{|c|c|c|c|c|c|c|c|c|c|c|c|c|c|c|}
\hline & $\begin{array}{l}\mathrm{PL} \\
L L\end{array}$ & $\begin{array}{c}\mathrm{PSP}^{2} \\
H L\end{array}$ & $\begin{array}{l}\mathrm{PL} \\
L L\end{array}$ & $\begin{array}{c}\mathrm{PSP}^{2} \\
H L\end{array}$ & $\begin{array}{l}\mathrm{PL} \\
L L\end{array}$ & $\begin{array}{c}\text { PSP } \\
H L\end{array}$ & $\begin{array}{l}\text { PL } \\
L L\end{array}$ & $\begin{array}{c}\mathrm{PSP}^{1} \\
H L\end{array}$ & $\begin{array}{c}\mathrm{PL}^{1} \\
L L\end{array}$ & $\begin{array}{c}\mathrm{PSP}^{1} \\
H L\end{array}$ & $\begin{array}{l}\mathrm{PL} \\
L L\end{array}$ & $\begin{array}{c}\mathrm{PSP}^{2} \\
H L\end{array}$ & $\begin{array}{c}\mathrm{PL}^{2} \\
L L\end{array}$ & \\
\hline 39 & 11 & 87,72 & 102,97 & 101,75 & 58,70 & 59,37 & 50,55 & 53,09 & 2,04 & 1,95 & 1,42 & 1,41 & 1,24 & 0,3 \\
\hline 42 & & & 08 & 100,40 & 66 & 58,58 & & ר? & 2,0 & & & & 2, & 0,83 \\
\hline 45 & 91,68 & 91,14 & 103,32 & 100,88 & 58,74 & 59,64 & 53,86 & 53 , & 1,9 & 1,8 & 33 & 1, & 0,72 & 81 \\
\hline 48 & 93,42 & 90,75 & 105,11 & 100,35 & 57,82 & 58,04 & 54, & 52,18 & 1,95 & 1,90 & 1,29 & 1, & 1,45 & 1.57 \\
\hline 51 & & & 106,60 & 100, & 9,27 & 59,62 & 51,75 & & 2,06 & 1,90 & TO & 1,3 & 1,45 &, 29 \\
\hline Médias & 89,01 & 89,88 & $104,22^{\mathrm{a}}$ & $100,78^{\mathrm{b}}$ & 58,64 & 59,05 & 52,18 & 52,97 & $2,00^{\mathrm{a}}$ & $1,90^{\mathrm{b}}$ & 1,38 & 1,35 & 1,40 & 0,70 \\
\hline
\end{tabular}

Means

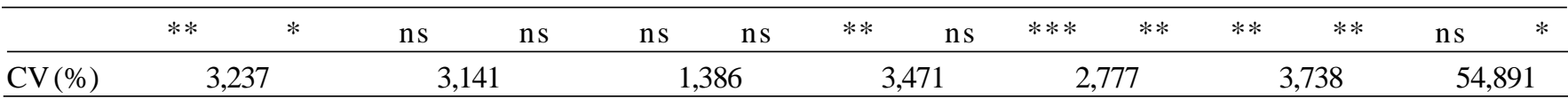

1 Efeito linear (Linear effect): * $(P<0,10) ;{ }^{* *}(P<0,05) ; * * *(P<0,01)$

2 Efeito quadrático (Quadratic effect): ${ }^{*}(P<0,10) ;{ }^{* *}(P<0,05) ;{ }^{* * \star}(P<0,01)$.

$a, b$ Letras diferentes indicam que as médias referentes às linhagens diferem pelo teste $F(P<0,05)$ (Different letters indicate that means of the strains are different by $F$ test).

Existiram diferenças entre as linhagens para consumo de ração e conversão por massa de ovos. A linhagem semipesada apresentou menor consumo e melhor conversão alimentar $(\mathrm{P}<0,05)$ que a linhagem leve.

Vários estudos têm indicado que as aves mais pesadas produzem ovos de maior tamanho (DOUGLAS e HARMS, 1982; SUMMERS e LEESON, 1993; KESHAVARZ e NAKAJIMA, 1995; e LEESON e SUMMERS, 1997).

O peso dos ovos não foi afetado pelos níveis de lisina, provavelmente, em virtude de as aves terem sido

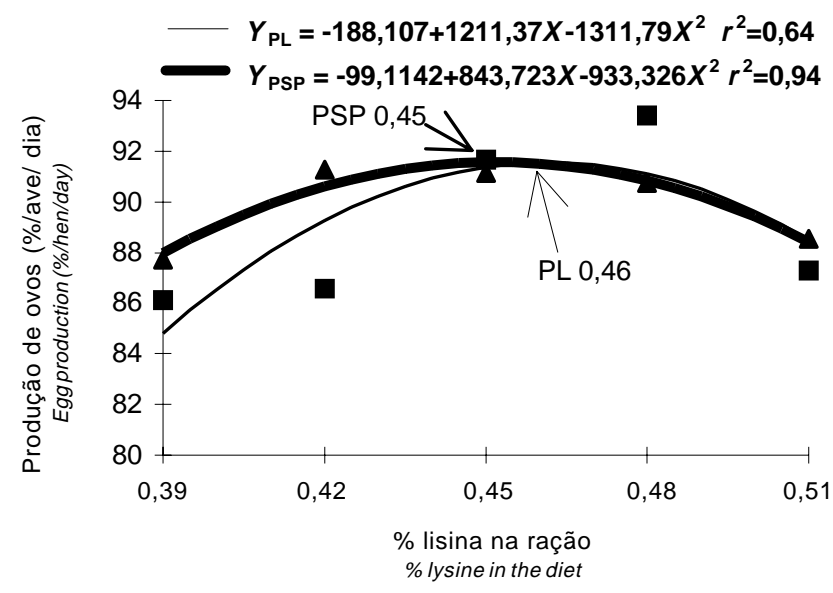

Figura 4 - Produção de ovos, em função dos níveis de lisina da ração de 13 a 20 semanas de idade.

Figure 4 - Egg production, in function of the dietary lysine level from 13 to 20 weeks of age. selecionadas para similar peso corporal. Este resultado reforça a afirmação anterior e sugere que a deficiência marginal de lisina na ração de crescimento final não deve afetar esta característica de modo importante.

A maior incidência de ovos quebrados no nível de $0,45 \%$ de lisina na ração das poedeiras semipesadas $(\mathrm{P}<0,10)$, conforme a equação quadrática: $y=-2,83291+12,9917 X-14,3931 X 2\left(r^{2}=0,86\right)$, foi inesperado. As poedeiras leves apresentaram maior quantidade de ovos quebrados que as semipesadas $(\mathrm{P}<0,05)$.

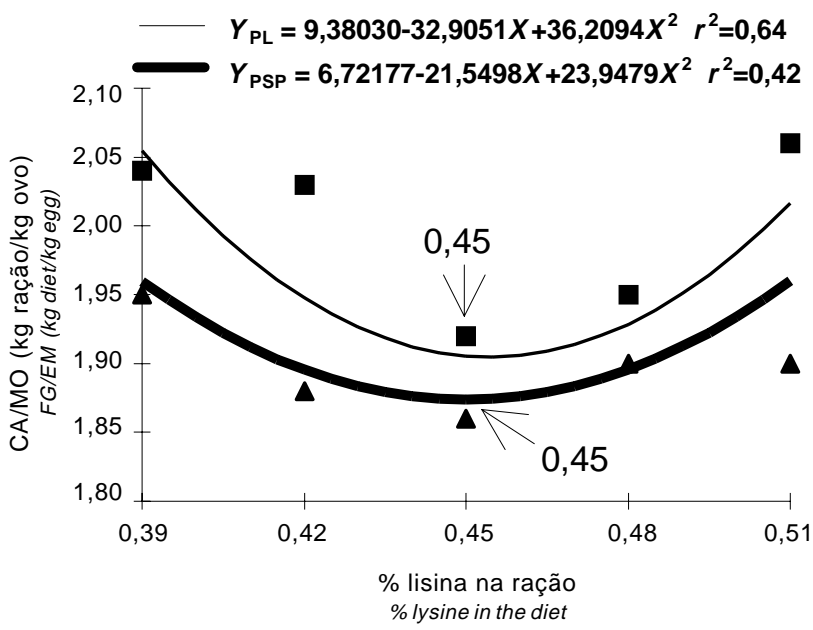

Figura 5 - Conversão por massa de ovos, em função dos níveis de lisina da ração de 13 a 20 semanas de idade.

Figure 5 - Egg mass conversion, in function of dietary lysine levels from 13 to 20 weeks of age. 


\section{Conclusões}

As exigências de lisina total para a fase de 13 a 20 semanas foram de $0,46 \%$ ou consumo de 354 mg diário, para as aves leves, e $0,49 \%$ ou consumo de $365 \mathrm{mg}$ diário para as semipesadas, correspondendo, respectivamente, a 315 e $325 \mathrm{mg}$ de lisina digestível diárias.

A deficiência de lisina na fase final do crescimento afeta de forma irreversível o desempenho produtivo das poedeiras comerciais.

\section{Referências Bibliográficas}

BAKER, D.H., HAN. Y. 1994. Ideal amino acid profile for chicks during the first three weeks posthathing. Poult. Sci., 73:1441-1447.

BERG, L.R. 1976. Lysine requirement of White Leghorn pullets from 8 to 21 weeks of age. Poult. Sci., 55:389-394.

CHARLES, D.R. Theoretical approaches to poultry housing in hot climates. In: WOURLD'S POULTRY CONGRESS, 19, 1992, Amsterdam. Proceedings ... Amsterdam, 1992, p.117-120.

CHI, M.S. 1985. Effect of low protein diets for growing leghorn pullets upon subsequent laying performance. Brit. Poult. Sci., 26:433-440.

CONNOR, J.K., FUELLING, D.E., BARRAM, K.M. 1977. Restriction of lysine and total feed intake of the pullet in the starter, grower and developer phases. Austr. J. Experim. Agric. Anim. Husb., 17:581-587.

COUCH, J.R., TRAMMELL, J., CREGER, C.R. 1967. Effect of low lysine diets on nutrition and rearing of broiler breeder replacement pullets. Poult. Sci., 46:1249.

DEVEGPWDA, G. Feeding and feed formulation in hot climates for layers. In: WOURLD'S POULTRY CONGRESS, 19, 1992, Amsterdam. Proceedings ... Amsterdam: 1992, p.77-79.

DOUGLAS, C.R., HARMS, R.H. 1982. The influence of low protein grower diets on spring housed pullets. Poult. Sci., 61:1885-1890.

FARIA, D. E., JUNQUEIRA, O.M. Nutrição e alimentação de poedeiras comerciais. In: SIMPÓSIO SOBRE NUTRIÇÃO ANIMAL E TECNOLOGIA DA PRODUÇÃO DE RAÇÕES, 1998. Campinas, SP. Anais ... Campinas, SP: 1998. p.77-95.

FLOCK, D.K. 1998. Genetic-economic aspects of feed efficiency in laying hens. World's Poult. Sci. J., 54:225-239.

JOHNSON, R.J., CUMMING, R.B., FARRELL, D.J. 1985. Influence of food restriction during rearing on the body composition of layer-strain pullets and hens. Brit. Poult. Sci., 26:335-348.

KESHAVARZ, K. 1984. The effect of different dietary protein levels in rearing and laying periods on performance of White Leghorn chickens. Poult. Sci., 63:2229-2240.

KESHAVARZ, K., NAKAJIMA, S. 1995. The effect of dietary manipulations of energy, protein, and fat during the growing and laying periods on early egg weight and egg components. Poult. Sci., 74:50-61.

KWAKKEL, R.P., KONING, F.L.S.M., VERSTEGEN, M.W.A., HOF, G. 1991. Effect of method and phase of nutrient restriction during rearing on productive performance of light hybrid pullets and hens. Brit. Poult. Sci., 32:747-761.

KWAKKEL, R.P. Nutritional studies on body development and performance in laying-type pullets and hens: a multiphasic approach. In: WOURLD'S POULTRY CONGRESS, 19, 1992, Amsterdam. Proceedings ... Amsterdam: 1992, p. $480-484$

LEESON, S., SUMMERS, J.D. 1997. Commercial poultry nutrition. 2.ed., Guelphy: Univ. Books. 350p.

MANUAL DE CRIAÇÃO E MANEJO - LOHMANN LSL. Granja Planalto-Lohmann. Uberlândia, MG. 1997. 23p.

MANUAL DA LINHAGEM ISA BROWN. Guía de manejo Ponedoras Isa Brown. 1996. 16p.

MARTIN, P.A., BRADFORD, G.D., GOUS, R.M. 1994. A formal method of determining the dietary amino acid requirements of laying-type pullets during their growing period. Brit. Poult. Sci., 35:709-724.

NATIONAL RESEARCH COUNCIL - NRC. 1994. Nutrient requirement of poultry. 9.ed., Washington, D.C.: National Academic Press. 155p.

PACK, M. Proteína ideal para frangos de corte. Conceito atual. In: CONFERÊNCIA APINCO DE CIÊNCIA E TECNOLOGIA AVÍCOLA, Curitiba, 1995. Anais... Campinas, SP: APINCO, 1995. p.95-110.

PENZ JR., A.M. Importância da utilização de uma ração adequada na formação da franga. In: SIMPÓSIO TÉCNICO DE PRODUÇÃO DE OVOS, 1, Campinas, SP, 1991. Anais ... Campinas, SP: APA, 1991. p.73-85.

ROSTAGNO, H.S., SILVA, D.J., COSTA, P.M.A. et al. 1983 Composição de alimentos e exigências nutricionais de aves e suínos: tabelas brasileiras. Viçosa, MG: UFV. 61p.

ROSTAGNO, H.S., BARBARINO JR., P. BARBOZA, W. Exigências nutricionais das aves determinadas no Brasil. In: SIMPÓSIO INTERNACIONAL SOBRE EXIGÊNCIAS NUTRICIONAIS DE AVES E SUÍNOS, 1996, Viçosa, MG. Anais... Viçosa, MG: UFV, 1996. p.361-388.

SHALEV, B.A. 1995. Comparison of white and brown egg shell laying stocks. World's Poult. Sci. J., 51:7-16.

SILVA, J.H.V., ALBINO, L.F.T., ROSTAGNO, H.S. et al 2000a. Exigência de lisina para aves de reposição de 0 a 6 semanas de idade. Rev. bras. zootec., 29:(6)1777-1785.

SILVA, J.H.V., ALBINO, L.F.T., ROSTAGNO, H.S. et al., 2000b. Exigência de lisina para aves de reposição de 7 a 12 semanas de idade. Rev. bras. zootec., 29:(6)1786-1794.

SUMMERS, J.D., LEESON, S, SPRATT, D. 1987. Rearing early maturing pullets. Poult. Sci., 66:1750-1757.

SUMMERS, J.D., LEESON, S. 1993. Factors influencing early egg size. Poult. Sci., 62:1155-1159.

UNIVERSIDADE FEDERAL DE VIÇOSA - UFV. 1982. Central de processamento de dados - UFV - CPD. SAEG - Sistema para análise estatística e genética. Viçosa, MG. 59p.

WELLS, R.G. Pullet feeding systems during rearing in relation to subsequent laying performance. Recent Advances in Animal Nutrition, 1980. p.185-202.

Recebido em: 02/12/99

Aceito em: 26/04/00 